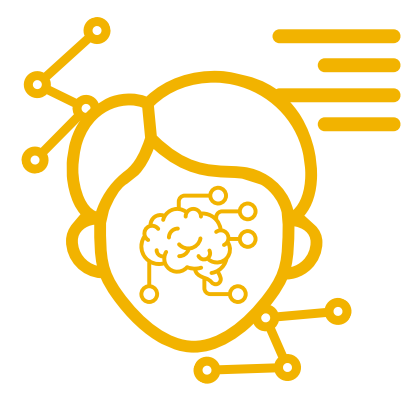

\title{
A COMUNICAÇÃO INTERNA EM UM HOSPITAL UNIVERSITÁRIO FEDERAL DA REDE EBSERH: OTIMIZANDO O PROCESSO USANDO APRENDIZADO DE MÁQUINA
}

INTERNAL COMMUNICATION IN A FEDERAL UNIVERSITY HOSPITAL OF THE EBSERH NETWORK: OPTIMIZING THE PROCESS USING MACHINE LEARNING

\section{Clarissa Oliveira de Carvalho}

Bacharel em Comunicação Social - Habilitação em Relações Públicas pela Universidade Federal de Santa Maria. Analista Administrativo - Relações Públicas da Empresa Brasileira de Serviços Hospitalares, lotada no Complexo Hospital de Clínicas da UFPR. Mestranda do Programa de Pós-Graduação em Gestão e Inovação em Saúde da Universidade Federal do Rio Grande do Norte. oliveira.carvalho@ebserh.gov.br

\section{Alysson José Ramos Casimiro}

Bacharel em Ciências e Tecnologia com ênfase em Telecomunicações, pela Universidade Federal do Rio Grande do Norte. Residente em Business Intelligence and Analytics no Tribunal de Contas do Rio Grande do Norte. alyssoncasimiro23@gmail.com

Hertz Wilton de Castro Lins

Doutor em Engenharia Elétrica e de Computação pela Universidade Federal do Rio Grande do Norte (UFRN). Professor Adjunto do Departamento de Engenharia de Comunicações da Universidade Federal do Rio Grande do Norte (UFRN). hertzw@gmail.com

Danilo Alves Pinto Nagem

Doutor em Engenharia Mecânica pela Universidade Federal de Minas Gerais (UFMG). Professor Associado da Universidade Federal do Rio Grande do Norte (UFRN). danilo.nagem@gmail.com

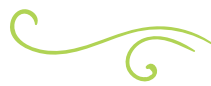

\section{RESUMO}

atual contexto de inovação tecnológica digital que a indústria 4.0 trouxe, gerando um gigantesco volume de dados, apresenta novos desafios para a comunicação interna das organizações. Os hospitais são instituições naturalmente complexas em virtude de sua diversidade de atividades, perfis de profissionais, tipos de públicos e regulamentações a ser seguidas, sendo um exemplo de instituição com demandas de gerenciamento de dados em larga escala. O perfil organizacional dos hospitais universitários e seu papel na sociedade instigaram a reflexão sobre a importância da qualidade das informações, a maneira como são divulgadas, bem como a forma como são recebidas pelo público interno, ou seja, sobre a eficácia na comunicação interna desse tipo de instituição, tendo em vista que isso vai impactar 
todos que lidam direta ou indiretamente com pacientes, influenciando nos resultados entregues, seja na formação acadêmica, seja na assistência de saúde. Nesse sentido, o estudo aponta que os processos referentes à comunicação interna nesse tipo de organização apresentam algumas dificuldades, como a falta de comunicação dirigida e a ausência de interatividade entre os diversos segmentos do público interno. O objetivo deste trabalho foi verificar as necessidades e carências do público interno de um grande hospital universitário (Complexo Hospital de Clínicas da Universidade Federal do Paraná) e fazer uma proposta de utilização de inteligência artificial como instrumento para realizar a comunicação dirigida, por meio de aprendizado de máquina. O estudo tem por base a pesquisa bibliográfica, quanti-qualitativa, considerando a amostra qualificada do público interno do Complexo Hospital de Clínicas (formado por profissionais e residentes de todas as áreas), bem como o desenvolvimento de uma prova de conceito para recomendação de conteúdo a partir de notícias disponibilizadas nos portais dessa instituição e da Empresa Brasileira de Serviços Hospitalares. Este trabalho proporcionou verificar a importância e as dificuldades que existem na comunicação interna de um grande hospital universitário, ao mesmo tempo que demonstrou que o uso de inteligência artificial, como gestão de dados e recomendação de conteúdo, bem como a inteligência coletiva e inteligência colaborativa podem ser uma solução viável e promissora para essas carências, inserindo esse tipo de organização na era da comunicação 4.0. e no contexto de hospital 4.0.

Palavras-chave: Comunicação4.0,Aprendizado de Máquina, Inteligência Coletiva, Inteligência Colaborativa, Hospital 4.0.

\section{ABSTRACT}

The current context of digital technological innovation that Industry 4.0 brought, generating a gigantic volume of data, poses new challenges for the internal communication of organizations. Hospitals are naturally complex institutions due to their diversity of activities, professional profiles, types of audiences and regulations to be followed, being an example of an institution with large-scale data management demands. The organizational profile of university hospitals and their role in society, prompted reflection on the importance of the quality of information, the way they are disseminated, as well as the way they are received by the internal public of a university hospital, that is, or, on the effectiveness in the internal communication of this type of institution, considering that it will impact everyone who deals directly or indirectly with patients, influencing the results delivered, whether in academic training or health care. However, it is observed that the processes refer to internal communication in this type of organization presents some difficulties such as a lack of directed communication and interactivity between the different segments of the internal public. The objective of this work was to verify the needs and needs of the internal public of a large university hospital (Complex Hospital de Clínicas of the Federal University of Paraná) and make a proposal to use artificial intelligence as an instrument to carry out targeted communication, through learning of machine. The study is based on bibliographic, quanti-qualitative research, considering the qualified sample of the internal public of the Hospital de Clínicas Complex (formed by professionals and residents from all areas), as well as the development of a proof of concept for content recommendation from news available on the portals of this institution and the Brazilian Hospital Services Company. This work allowed to verify the importance and the difficulties that exist in the internal communication of a great university hospital, while allowing the use of artificial intelligence, such as data management and content recommendation, as well 
as collective intelligence and collaborative intelligence can be a viable and promising solution to these needs, this type of organization in the age of communication 4.0 and in the context of hospital 4.0.

Key-words: Communication 4.0, Collective Intelligence, Collaborative Intelligence, Hospital 4.0, Machine Learning.

\section{INTRODUÇÃO}

Muito mais do que proporcionar conhecimento, entendimento e compreensão entre emissor e receptor, a comunicação gera valor. É o valor de uma instituição que a torna grande, competitiva, respeitada e admirada em seu meio e pelas pessoas que as fazem existir, gerando comprometimento e bons resultados. Geralmente, a comunicação é vista como um meio para potencializar a gestão de empreendimentos. Apesar de essa ser uma das funções da comunicação organizacional, é necessário observá-la como um processo que leve ao desenvolvimento de instituições e pessoas, gerando conhecimento e transformando padrões de comportamento (MARCHIORI, 2010). Chegamos à quarta Revolução Industrial em que a forma como nos comunicamos, trabalhamos e vivemos mudou drasticamente e de forma irreversível. Também chamada de Indústria 4.0, a nova era utiliza recursos como inteligência artificial, big data, robôs, internet das coisas e impressão $3 \mathrm{D}$, que fazem parte de nossas rotinas e estão invadindo o universo organizacional, trazendo muitas transformações para a sociedade.

O impacto da Indústria 4.0 vai além dos processos de digitalização, imprimindo muito mais complexidade às inovações que surgem de múltiplas tecnologias combinadas, o que força as empresas a repensarem suas gestões (COELHO, 2016). As instituições, sejam elas de grande ou pequeno porte, públicas ou privadas, precisam se engajar nesse panorama ou poderão entrar em um processo de estagnação e entropia.
Assim como os demais sistemas das organizações precisam se adequar aos novos cenários para manterem sua eficácia e atenderem as necessidades e expectativas de seus públicos, a comunicação organizacional também necessita avançar. Porém, encontramos alguns obstáculos para acompanhar esses avanços, como a resistência de gestores e profissionais para trabalhar a partir desses novos paradigmas.

A natureza humana não muda na mesma escala de tempo que as inovações tecnológicas e os padrões de comportamento demoram a mudar (THIMBLEDY, 2013). Por isso, a comunicação organizacional é mais complexa do que parece e vai além da produção e divulgação de boletins e comunicados, pois precisa ser estratégica e pensada para construir novos parâmetros de relacionamento e comprometimento.

O atual contexto de inovação tecnológica que a indústria 4.0 trouxe com a gigantesca quantidade de dados gerados a todo instante traz novos desafios para a comunicação interna das organizações. Os metadados (dados sobre dados) entram em cena gerando informações decisivas e possibilitando traçar estratégias a partir do conhecimento que proporcionam construir.

Os hospitais são instituições naturalmente complexas em virtude de sua diversidade de atividades, perfis de profissionais, tipos de públicos e regulamentações a ser seguidas. De acordo com o Ministério da Educação, uma das instituições mantenedoras e reguladoras dos hospitais universitários, "os hospitais universitários são centros de formação de recursos humanos e de desenvolvimento de tecnologias na área de saúde" (MINISTÉRIO DA EDUCAÇÃO, 2020). Hospitais universitários precisam gerenciar não só a parte de ensino, pesquisa e extensão, mas também todas as questões relativas à área assistencial, o que traz um volume ainda maior de dados. "A efetiva prestação de serviços à população possibilita o aprimoramento constante do atendimento e a elaboração de protocolos técnicos para diversas patologias" 
(MINISTÉRIO DA EDUCAÇÃO, 2020). O perfil organizacional dos hospitais universitários e seu papel na sociedade nos levaram a refletir sobre a importância da qualidade das informações e a maneira como são divulgadas pela instituição e recebidas pelo público interno, ou seja, a eficácia na comunicação interna, tendo em vista que esta vai impactar todos que lidam direta ou indiretamente com pacientes, influenciando nos resultados entregues por essas instituições, tendo em vista que a formação acadêmica e a assistência de saúde são a missão dos HU's.

Porém, a partir das análises realizadas no Complexo Hospital de Clínicas da Universidade Federal do Paraná (UFPR), ao longo deste trabalho, observou-se que os processos referentes à comunicação interna nos hospitais universitários federais apresentam algumas dificuldades. Os veículos de comunicação disponíveis não permitem executar ações dirigidas, ou seja, todas as informações chegam a todos os segmentos do público interno ao mesmo tempo, como ocorre na comunicação de massa. $O$ usuário não tem como filtrar a informação de seu interesse. Isso acaba por gerar outro problema, que é a falta de engajamento dos profissionais e residentes, devido ao excesso de informações recebidas por e-mail, por exemplo. A falta de interatividade e possibilidade de feedback do público interno e a ausência de troca de informações entre os diversos níveis e fluxos também são problemas identificados. A alta gestão não tem como avaliar as reações de suas equipes perante as informações divulgadas diariamente e que causam impactos nas rotinas de todos os que atuam no ambiente. Acaba-se por executar uma comunicação que não dá voz aos receptores, tratando todos os segmentos do público interno de forma igualitária, sem considerar as suas peculiaridades, o que gera pouco engajamento e até mesmo repulsa.

É como se ainda estivéssemos na era da Teoria da Agulha Hipodérmica ou Teoria da Bala Mágica, um conceito de comunicação de massa da década de 1930, que se baseia na hipótese de que os estímulos gerados por mensagens enviadas afetam todos os indivíduos igualmente, sem causar resistência, assim como o disparo de uma arma de fogo ou uma agulha hipodérmica ao perfurar a pele humana sem dificuldade.

O termo "Teoria Hipodérmica" sugere um receptor passivo que apenas absorve os conteúdos de um emissor onipotente (LUERSEN, 2013). Diante desse cenário e das possibilidades que a inteligência artificial nos permite, novas soluções precisam fazer parte dos protocolos de comunicação interna dessas instituições. A comunicação 4.0, que possibilita "transmitir informação verbal ou não verbal, com base na análise e compreensão dos dados originados pelas múltiplas fontes, de origens diferentes" (PENHAKI, 2019, p. 96), pode ser uma alternativa para alavancar soluções de problemas a partir da gestão de dados e inteligência coletiva e colaborativa, que utilizam a recomendação de conteúdo como ferramenta para apresentar conteúdos de acordo com o perfil e o interesse de cada usuário.

O objetivo deste trabalho foi verificar as necessidades e carências do público interno de um grande hospital universitário da rede Ebserh (Complexo Hospital de Clínicas da UFPR) e fazer uma proposta de utilização de aprendizado de máquina como instrumento para realizar a comunicação dirigida, por meio de recomendação de conteúdo. Visando responder à questão "como a comunicação interna de um hospital universitário federal pode se tornar mais efetiva utilizando elementos da comunicação 4.0?", este estudo pautou-se em referências bibliográficas, pesquisa quanti-qualitativa considerando a amostra qualificada do público interno do Complexo Hospital de Clínicas da Universidade Federal do Paraná (formado por profissionais e residentes de todas as áreas), bem como o desenvolvimento de uma prova de conceito para aprendizado de máquina a partir de notícias disponibilizadas nos portais do CHC-UFPR e Ebserh, que foram 
classificadas por tipos e escalas de interesse de acordo com a área de atuação dos segmentos do público interno.

Este trabalho proporcionou verificar a importância e as dificuldades que ainda existem na comunicação interna de instituições complexas como hospitais universitários, ao mesmo tempo que demonstrou como o uso de inteligência artificial, como gestão de dados e aprendizado de máquina, pode ser uma solução viável e promissora para essas carências, inserindo essas organizações na era da comunicação 4.0. A pesquisa aplicada ao público interno do Complexo Hospital de Clínicas da UFPR possibilitou confirmar algumas características sobre $\mathrm{O}$ comportamento dos profissionais e residentes em relação à comunicação interna de um grande hospital universitário da Empresa Brasileira de Serviços Hospitalares (Ebserh), bem como suas necessidades e desejos relativos a essa questão. Ao analisarmos os veículos de comunicação disponíveis no CHC-UFPR, verificamos que não há como realizar, atualmente, uma comunicação dirigida e focada em apresentar feedbacks para a gestão e para o público interno. A partir dessa premissa, foi realizada uma prova de conceito com três tipos de algoritmos que demonstrou como o aprendizado de máquina é eficaz para a realização de recomendação de conteúdo, a segmentação de informações e a viabilidade da comunicação dirigida, que, por sua vez, vai ao encontro das características da comunicação 4.0 ao utilizar inteligência artificial e gestão de dados, possibilitando promover o desenvolvimento de um veículo de comunicação que gere assertividade, colaboração e feedback.

\section{MÉTODOS}

A presente pesquisa visa responder à pergunta "como a comunicação interna de um hospital universitário federal pode se tornar mais efetiva utilizando elementos da comunicação 4.0?". O método utilizado para a realização deste estudo foi a pesquisa-ação com abordagem quanti-qualitativa, desenvolvida no Complexo Hospital de Clínicas da Universidade Federal do Paraná (CHCUFPR) entre os meses de julho a outubro de 2020. Por meio de amostra qualificada, foram aplicados questionários semiestruturados que tiveram como público-alvo os profissionais com vínculos Ebserh e RJU das áreas médica, assistencial e administrativa, residentes médicos e residentes multiprofissionais do CHC-UFPR. A amostra abrangeu homens e mulheres, das mais diversas profissões exercidas no CHC-UFPR, com faixas etárias diversificadas e atuação tanto no Hospital de Clínicas quanto na maternidade Victor Ferreira do Amaral (hospitais que compõem o CHC-UFPR), nos turnos diurno e noturno. $\bigcirc$ questionário teve como objetivo verificar a percepção do público interno do Complexo HC-UFPR em relação aos veículos e procedimentos de comunicação interna da instituição, visando identificar quais as necessidades e dificuldades do público interno em relação ao acesso às informações institucionais, bem como conteúdos de interesse. Este trabalho foi aprovado pelo Comitê de Ética em Pesquisa em Seres Humanos do CHC-UFPR por meio do CAEE $n^{\circ}$ 36876620.0.0000.0096, seguindo os preceitos estabelecidos na Resolução $N^{\circ} 466$, de 12 dezembro de 2012, do Ministério da Saúde, em relação aos aspectos éticos de pesquisas envolvendo seres humanos.

A pesquisa utilizou os dados recolhidos a partir dos questionários disponibilizados com a ferramenta google forms. Também avaliou os atuais veículos de comunicação interna do Complexo HC, por meio de acesso ao site de intranet da Instituição, verificação de boletins diários, informes para tela de descanso dos computadores e TV disponível em área de circulação coletiva, bem como consulta com a equipe da Unidade de Comunicação do CHC-UFPR. O método proposto foi escolhido em virtude de proporcionar uma análise da percepção dos profissionais e residentes do CHC-UFPR e suas respectivas opiniões acerca 
da comunicação interna da instituição a partir de dados gerados pelos questionários, com a praticidade necessária diante da rotina de um grande hospital universitário, rápida e eficaz o suficiente para o que o estudo se propõe.

Também foi realizada pesquisa bibliográfica com o objetivo de analisar a produção científica disponível e contextualizar a comunicação interna a partir da comunicação 4.0, para verificar suas aplicabilidades em hospitais universitários federais visando obter mais efetividade organizacional. As seguintes etapas foram percorridas: estabelecimento da pergunta da pesquisa, definição dos descritores, definição dos critérios de inclusão e exclusão, triagem dos artigos após a leitura dos resumos, seleção dos artigos após a leitura completa, extração dos dados, avaliação, síntese e interpretação das informações.

Foram selecionados artigos nacionais e internacionais e também foi feita consulta em livros que abordam a temática e sites que trazem questões relativas à comunicação 4.0, já que esse tema ainda é escasso na literatura científica. Como critérios de inclusão foram definidos: artigos e livros com até dez anos de publicação, abordagem de comunicação interna apenas com viés institucional/organizacional, hospital 4.0 no contexto da comunicação interna e não especificamente em relação aos seus conceitos operacionais e assistenciais, inteligência coletiva e colaborativa relacionada ao ambiente organizacional e não com foco nas técnicas e na natureza de inteligência artificial. Também foram utilizados documentos relativos à gestão e à comunicação da Ebserh, bem como referências sobre recomendação de conteúdo.

Os critérios determinantes para exclusão referem-se a ambiguidade e apresentação insuficiente de resultados, estudos de revisão, comunicações, relatos de casos, resumos de eventos científicos, monografias, comentários e editoriais. $O$ estudo foi guiado por cinco descritores pesquisados em português, inglês e espanhol, entre os meses de junho e outubro de 2019. Os atuais veículos de comunicação interna do CHC-UFPR foram avaliados com o apoio da Unidade de Comunicação Social da instituição, em relação aos tipos de conteúdos disponibilizados, alcance e frequência das informações destinadas ao público interno.

Para verificar como a gestão de dados e a comunicação dirigida possibilitada por meio do aprendizado de máquina podem ser eficazes e importantes componentes da comunicação 4.0, também foi realizada uma prova de conceito por meio de testes com três algoritmos que foram treinados para recomendar conteúdos de acordo com sua classificação prévia, bem como dos públicos-alvo e seus níveis de interesse. Essa classificação foi baseada em conteúdos (notícias) disponíveis nos portais de Internet do Complexo-HC da UFPR e Empresa Brasileira de Serviços Hospitalares (Ebserh), cinco categorias de público (área médica, área assistencial, área administrativa, residentes médicos e residentes multiprofissionais) e níveis de interesse entre 0 e 2 , sendo 0 neutro ou sem interesse, 1 interesse geral e 2 interesse máximo.

A classificação foi utilizada visando automatizar o processo de seleção de conteúdo atribuindo classes às notícias: ensino, assistência, gestão, institucional, inovação, geral, eventos institucionais, humanização, eventos/treinamentos, campanhas e Ebserh. Dessa forma, as notícias mais relevantes foram classificadas de acordo com cada perfil profissional viabilizando sua seleção e encaminhamento em virtude da sua relevância para cada segmento.

\section{REFERENCIAL TEÓRICO}

\section{Comunicação interna: o centro dos sistemas de gestão organizacional}

A comunicação interna é uma indispensável ferramenta de gestão. É a transmissão de informações de uma instituição e respectivas 
lideranças a seus funcionários, bem como destes com a governança e também entre si. Juntamente às políticas de administração de recursos humanos, a comunicação interna desempenha uma função estratégica na construção de simbologias que se dispõem a integrar os públicos aos princípios e objetivos centrais da empresa (CURVELLO, 2012).

Trata-se de ações que compreendem o relacionamento dos profissionais com a instituição, as relações entre os diversos setores, envolvendo a gestão, as conjunturas, as práticas discursivas e o contexto cultural. Abrange todas as possibilidades de troca e compartilhamento de informações, de vivências e experiências relacionadas a políticas, normas, regulamentos, procedimentos e objetivos da organização. A comunicação interna é muito mais do que processos informativos, pois envolve o conjunto de comportamentos e atitudes dos envolvidos.

Manter a coesão interna ao informar, mobilizar e educar, a partir dos valores organizacionais que devem ser compartilhados e reconhecidos para a construção de uma boa imagem pública também faz parte dos resultados almejados pelo conjunto de ações de comunicação interna (CURVELLO, 2012). A comunicação interna é geralmente classificada em três categorias: comunicação administrativa (documentos administrativos como memorandos e cartas circulares), comunicação social (engloba veículos de comunicação como boletins, jornais internos e intranet) e comunicação interpessoal (comunicação entre funcionários e gestores) (CURVELLO, 2012).

A presente pesquisa trabalha essencialmente baseada na comunicação social, pois se destina a avaliar a comunicação interna a partir dos conteúdos e comportamentos do público de acordo com os veículos disponíveis no Complexo Hospital de Clínicas da UFPR. São diversos os fluxos comunicacionais em um ambiente interno e estes acontecem em todos os níveis de uma organização. Dessa forma, todos os componentes do público interno tornam-se agentes de comunicação, sendo também responsáveis pela formação da identidade e imagem das instituições à medida que recebem e repassam dados, engajam-se em conceitos estabelecidos pela governança e refletem tudo isso em suas atividades e postura frente aos demais públicos.

Os fluxos de comunicação interna são divididos em quatro tipos: ascendente, descendente, horizontal e transversal (CURVELLO, 2012). Geralmente, o fluxo descendente predomina nas empresas, que costumam enviar informações da alta gestão aos quadros de funcionários por meio de boletins e jornais internos. O fluxo ascendente é o que parte dos funcionários para os gestores; e o horizontal é o que ocorre entre pares ou setores, quase sempre de maneira informal. Já o fluxo transversal traz a possibilidade de amenizar a distância entre níveis hierárquicos ao possibilitar a comunicação, em todas as direções, independentemente de função ou classe do profissional (CURVELLO, 2012). Produtividade, alcance de objetivos estratégicos e motivação dos empregados para trabalhar com comprometimento à causa de uma instituição dependem diretamente da efetividade da comunicação interna. Apesar de seu planejamento e sua construção serem constantes nas organizações que prezam pela qualidade e entrega de resultados efetivos, ainda se observa que há pouca atenção para a inovação nas suas práticas.

É importante tratar esse tipo de comunicação como item essencial para o sucesso de uma organização. Afinal, os seus colaboradores são influenciados pela maneira como são alcançados pela comunicação interna, gerando motivação para trabalhar em prol das metas estabelecidas, transformando-os em grandes aliados. Porém, para que isso ocorra, os empregados precisam se sentir parte da instituição. "Aquilo que eu quero que o meu cliente sinta, eu preciso fazer antes com que o colaborador sinta" (COSTA, 2015, p. 45). São os profissionais que dão vida às empresas e que devem ser 
prioridade em todos os processos de gestão, incluindo a comunicação interna, que assume a função de termômetro para o relacionamento entre instituições e empregados e se reflete diretamente na qualidade do produto ou serviço a ser entregue ao público externo.

"A efetividade da comunicação interna não é determinada pelo processo ou pela pauta comunicada. Ela é definida pelos atributos que essa comunicação tem na percepção dos colaboradores e pela forma como a organização transaciona a informação" (COSTA, 2015, p. 50). Nesse sentido, deve-se atentar também para a quantidade das informações repassadas ao público interno e a importância de fazer a comunicação de forma dirigida, de acordo com os interesses de cada segmento de público. A comunicação interna ideal deve ter um equilíbrio entre seus extremos, pois comunicar pouco gera especulações e falta de confiança, assim como o excesso de informações pode gerar uma sobrecarga que traz como resultado a indiferença ao que está sendo recebido (WHITE; VANCE; STAFFORD, 2020).

Uma pesquisa realizada na Universidade de Tennessee relata que "administradores admitiram que geralmente não têm uma noção clara do que é conhecimento comum entre os funcionários e que informações precisam ser transmitidas" (WHITE; VANCE; STAFFORD, 2020, p. 12). Eles também admitem que nem sempre sabem o que acontece com as informações depois que elas atingem o próximo nível abaixo delas. "Vazios de informações são criados quando os supervisores assumem que os funcionários já foram informados por outros canais" (WHITE; VANCE; STAFFORD, 2020, p. 12). Ou seja, observa-se que ocorrem grandes falhas durante o processo comunicacional que acabam por impedir as articulações necessárias entre os diversos níveis do público interno e a garantia de que a informação emitida surtirá os resultados almejados. Para obter sucesso na comunicação interna, deve-se levar em consideração tanto as necessidades e expectativas do público interno quanto o efetivo potencial de resultados almejados por meio dos recursos disponíveis para o processo comunicacional.

\section{Inteligência coletiva e inteligência colaborativa}

Vivemos um momento em que dados e informações estão por toda parte e crescem vertiginosamente em todos os setores da sociedade. Diariamente, são gerados cerca de 2,5 quintilhões de bytes ao redor do mundo (DAVENPORT, 2017). Palavras, números, comportamentos e sentimentos humanos podem se tornar dados. Uma imagem também pode se tornar um dado, que, ao ser analisado, vem a se transformar em informação e em conhecimento.

Administrar todo esse volume de dados torna-se um grande desafio para as organizações, que estão em direção a um destino sem volta para conseguirem manter suas operações otimizadas e uma gestão de qualidade: é o Big Data. "Big data é um termo genérico para dados que não podem ser contidos nos repositórios usuais; refere-se a dados volumosos demais para caber em um único servidor; não estruturados demais para se adequar a um banco de dados organizado em linhas e colunas" (DAVENPORT, 2017). A IBM possui um conceito que baseia - Big Data em 4 Vs: volume, variedade, velocidade e veracidade, conforme figura a seguir (GOMES; BRAGA, 2017). 


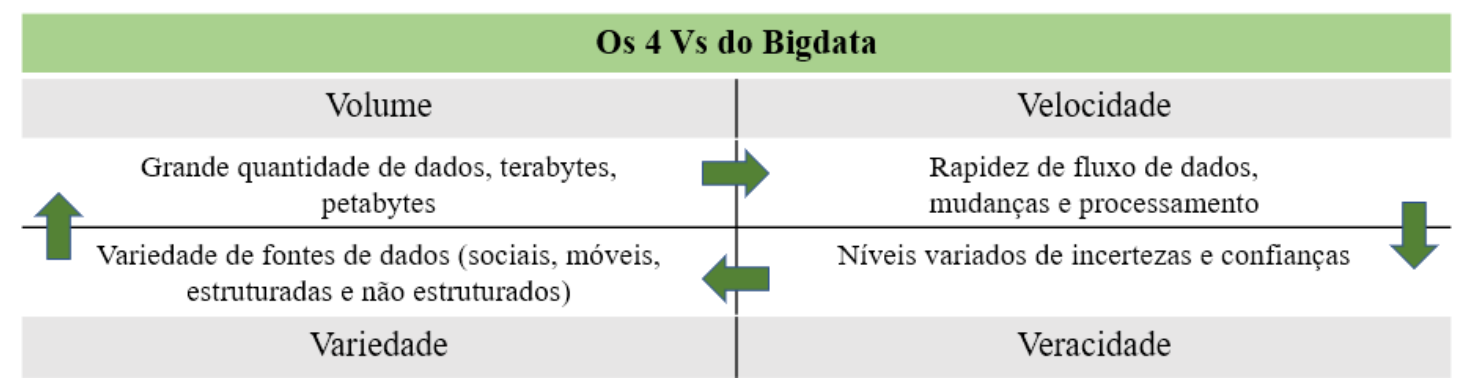

Figura 1 - Os 4 Vs do Big Data

Fonte: Gomes e Braga (2017).

É preciso observar que "o mais importante é não se deixar deslumbrar com o volume de dados, mas sim analisá-los para convertê-los em conhecimento, inovação e valor" (DAVENPORT, 2017, p. 2). Nem todos os dados disponíveis são relevantes ou serão aproveitados pelas organizações. Nesse sentido, a estruturação de dados torna-se indispensável para que se possa extrair valor deles para usá-los estrategicamente na gestão organizacional.

A partir do momento em que os dados são transformados em informações, as decisões já podem ser tomadas, isto é, há determinado conteúdo que já pode servir de subsídio para a tomada da decisão. A informação e o conhecimento combinados tornam-se fatores críticos de sucesso para ação e tomada de decisão (GOMES; BRAGA, 2017). Ou seja, além da estruturação, a análise dos dados que são realmente válidos para uma instituição constitui-se em um importante suporte de gestão, podendo refletir em melhorias para produtividade, qualidade de serviços, custos e recursos humanos. A partir desse extenso cenário, é preciso considerar os demais processos que precisam estar alinhados à captação, à estruturação, à análise e à forma como esses dados serão utilizados.

A aplicação de todo o conhecimento gerado necessita antes de tudo estar em sincronia com o público interno das organizações, pois esse segmento, além de ser um grande gerador de dados, é que vai operacionalizar as tomadas de decisão. Para isso, uma comunicação interna efetiva é primordial e, apesar de algumas empresas ainda executarem sua comunicação interna de forma verticalizada, já é ultrapassado considerar os colaboradores apenas como receptores de informações e diretrizes das empresas, sem direito à participação nos processos decisórios.

"O poder e a informação possuem conexão na medida em que a equação que relaciona maior nível de conhecimento à maior possibilidade de poder" (GOMES; BRAGA, 2017, p. xxii). A relação entre a disponibilidade e posse da informação e poder vem mudando em razão da possibilidade de acesso à "dispositivos altamente inteligentes que permitem que a recepção de informação aconteça paralelamente à produção de conteúdo, além do desenvolvimento de novos meios que permitem a comunicação a qualquer tempo e distância" (GOMES; BRAGA, 2017, p. xxiii).

Trata-se da inteligência coletiva e inteligência colaborativa que, diante da atual conjuntura da comunicação, da geração de dados e informações, constituem-se ferramentas estratégicas para uma comunicação interna efetiva e que corresponda às necessidades das organizações da atualidade. A inteligência coletiva é "[...] uma inteligência distribuída por toda parte, incessantemente valorizada, coordenada em tempo real, que resulta em uma mobilização efetiva das competências" (LÉVY, 2003, p. 28). Ela visa ao reconhecimento das habilidades que se distribuem nos indivíduos a fim de coordená-las para ser usadas em prol da coletividade. A coordenação dos inteligentes coletivos 
ocorre com a utilização das tecnologias da informação e comunicação.

A inteligência coletiva é construída a partir de saberes individuais que vão ao encontro de outras capacidades e, dessa forma, permitem uma democratização da informação e do conhecimento a partir de tecnologias digitais. Já a inteligência colaborativa promove a interação entre os envolvidos, ou seja, não basta disponibilizar informações, é preciso gerar trocas. Assim, a principal diferença entre inteligência coletiva e colaborativa pode ser descrita como a presença ou a falta de intercâmbio.

As tecnologias colaborativas servem para dar suporte à colaboração entre equipes que podem vir a estar em locais físicos diferentes. No entanto, para praticar a colaboração de conhecimento, é necessário utilizar os canais adequados. $O$ compartilhamento e a transferência de conhecimento "podem funcionar eficientemente somente no caso em que as ferramentas corretas de comunicação são usadas e quando são usadas no ambiente e contexto certos" (SARKA, 2014, p. 50).

\section{Comunicação e saúde na era 4.0}

Desde o início desta década, estamos vivendo a Quarta Revolução Industrial ou Indústria 4.0, em que os processos passam a ser automatizados por meio da informatização, proliferação de dispositivos inteligentes interconectados e gestão baseada em análise de dados (Big Data). Essas transformações atingem não só a indústria propriamente mas também geram impacto em todos os segmentos corporativos que precisam se adaptar às novas circunstâncias tecnológicas, culturais e laborais e atuar com dispositivos e tecnologias digitais cada vez mais avançadas como inteligência artificial, por exemplo. Os hospitais caminham aos poucos para essa nova realidade que já está presente em alguns processos que envolvem profissionais da saúde e pacientes, incluindo personalização e virtualização.
O conceito de Saúde 4.0 pode ser definido como uma derivação da indústria 4.0. Esse conceito também pode ser chamado de saúde digital, saúde eletrônica ou saúde inteligente. (BAUSE et al., 2019). "Resumidamente, a Saúde 4.0 pode ser descrita como um fenômeno para melhorar o serviço de saúde e a conectividade entre as partes interessadas na saúde, usando a tecnologia" (BAUSE et al., 2019, p. 888). Nesse sentido, para que os hospitais possam lidar com os conceitos já mencionados, é necessário redesenhar os processos hospitalares rumo a essa inovação que pode ser chamada de hospital 4.0. Porém, essa transformação não ocorrerá sem que haja também uma mudança cultural das equipes, o que envolve uma visão ousada e um forte compromisso de todos os componentes do público interno.

Isso implica ainda uma transformação do cuidado centrado no paciente para a abordagem centrada no paciente, possibilitada pela inovação tecnológica nos sistemas hospitalares e relações entre profissionais, pacientes e seus familiares, de forma colaborativa, possibilitando a tomada de decisões alinhadas com as famílias e de acordo com as necessidades e preferências dos pacientes (PIERANGELO; MERONE; SODA, 2018). Assim, o hospital 4.0 traz não só inovação tecnológica mas também metodológica, que para ser plenamente concretizada, também precisa do suporte de protocolos de comunicação bem estabelecidos e legitimados junto ao público interno.

Considerando todas essas questões e o "cenário 4.0", a comunicação deve acompanhar o processo de inovação, adaptando suas práticas e criando novas possibilidades de interação. Apesar de ainda ser pouco discutida e até mesmo utilizada, a comunicação 4.0 chegou para transformar a realidade de todos os tipos de organizações (incluindo os hospitais), trazendo as adaptações necessárias para as conjunturas desta nova era.

A comunicação 4.0 "deve propiciar a conexão entre homem-homem, homem-máquinas, 
máquina-máquina, respeitando a aplicação do conhecimento, das atitudes e dos valores e promovendo a leitura das inteligências humanas e de máquina" (PENHAKI, 2019, p. 96). Pode ser definida como uma soft skills fundamental para o bom desempenho profissional no cenário da indústria 4.0, uma habilidade necessária para alcançar resultados positivos diante dessa conjuntura (PENHAKI, 2019) "Para lidar com a interoperalidade e conectividade, precisa ser objetiva, assertiva e rápida para, inclusive lidar com a alta complexidade em escalas espaciais e temporais" (PENHAKI, 2019, p. 96). Toda tecnologia disponível para melhorar os processos corporativos necessita de profissionais que consigam adaptar-se às novas demandas com habilidades pessoais que vão ao encontro de tamanha revolução, como capacidade colaborativa, adaptação às mudanças constantes e flexibilidade para aprender, desaprender e reaprender.

Considerando essas habilidades ou competências profissionais e as tecnologias que proporcionam automatização e colaboração, a comunicação 4.0 precisa ser um sistema, um protocolo alinhado à cultura organizacional e com exímio apoio da governança. Inovação tecnológica sem engajamento de equipes; inteligência colaborativa sem participação ativa da gestão; governança comprometida com resultados efetivos, mas sem reciprocidade do público interno, são circunstâncias que dificultam a implementação da comunicação 4.0.

Por isso, é preciso a união de todas essas características. Assim, a comunicação 4.0 pode ser definida como um conjunto de práticas de comunicação que por meio das tecnologias desenvolvidas na indústria 4.0, do engajamento dos públicos com base na inteligência coletiva e colaborativa, do apoio interativo da governança e da curadoria de profissionais de comunicação social, gera o entendimento mútuo e democrático, com instantaneidade, liberdade e acessibilidade ampliada, facilitando a tomada de decisões e proporcionando adequação das informações com sistemas de recomendação de conteúdo, mais integração entre pessoas bem como mensuração de resultados por meio da análise de dados.

No quadro a seguir, estão listadas as características e tecnologias da Indústria 4.0, Hospital 4.0 e Comunicação 4.0 para melhor compreensão da conexão entre os três conceitos.

Quadro 1 - Características, tecnologias e processos de comunicação interna na Indústria 4.0, Hospital 4.0 e Comunicação 4.0

\begin{tabular}{|l|l|l|l|}
\hline \multicolumn{1}{|c|}{ Tecnologias } & \multicolumn{1}{|c|}{ Características } & \multicolumn{1}{|c|}{ Processos de comunicação interna } \\
\hline Indústria 4.0 & $\begin{array}{l}\text { Internet das coisas, } \\
\text { realidade ampliada, } \\
\text { robôs, drones, inteligência } \\
\text { artificial, aprendizado } \\
\text { de máquina, big data, } \\
\text { impressão 3D, computação } \\
\text { em nuvem, sensores de } \\
\text { visão, toque e som. }\end{array}$ & $\begin{array}{l}\text { Processo automatizado, } \\
\text { análise de dados, tomada } \\
\text { de decisão assertiva, } \\
\text { mensuração de resultados, } \\
\text { interoperabilidade, } \\
\text { descentralização, } \\
\text { virtualização. }\end{array}$ & $\begin{array}{l}\text { Segmentação de públicos, } \\
\text { alinhamento de interesses e tomada de } \\
\text { decisão assertiva por meio de aprendizado } \\
\text { de máquina e recomendação de conteúdo. }\end{array}$ \\
\hline
\end{tabular}




\begin{tabular}{|l|l|l|l|}
\hline Hospital 4.0 & $\begin{array}{l}\text { Internet das coisas, } \\
\text { realidade ampliada, robôs, } \\
\text { big data, impressão 3D, } \\
\text { computação em nuvem, } \\
\text { sensores de visão, toque } \\
\text { e som, aprendizado de } \\
\text { máquina. }\end{array}$ & $\begin{array}{l}\text { Processo automatizado, } \\
\text { análise de dados, tomada } \\
\text { de decisão assertiva, } \\
\text { inteligência coletiva, } \\
\text { inteligência colaborativa, } \\
\text { mensuração de resultados, } \\
\text { interoperabilidade, } \\
\text { virtualização. }\end{array}$ & $\begin{array}{l}\text { Empoderamento de todos os segmentos } \\
\text { do público interno por meio da inteligência } \\
\text { colaborativa, geração de conteúdo por } \\
\text { todos os segmentos, recomendação de } \\
\text { conteúdo, decisões assertivas. }\end{array}$ \\
\hline $\begin{array}{l}\text { Comunicação } \\
\mathbf{4 . 0}\end{array}$ & $\begin{array}{l}\text { Internet das coisas, } \\
\text { realidade ampliada, } \\
\text { robôs, drones, inteligência } \\
\text { artificial aprendizado } \\
\text { de máquina, big data, } \\
\text { impressão 3D, computação } \\
\text { em nuvem, sensores de } \\
\text { visão, toque e som. }\end{array}$ & $\begin{array}{l}\text { Processo automatizado, } \\
\text { análise de dados, tomada } \\
\text { de decisão assertiva, } \\
\text { inteligência coletiva, } \\
\text { inteligência colaborativa, } \\
\text { recomendação de } \\
\text { conteúdo, mensuração de } \\
\text { resultados, Virtualização. }\end{array}$ & $\begin{array}{l}\text { Rede social corporativa, comunicação } \\
\text { realizada em todos os níveis e fluxos, } \\
\text { instantaneidade (para consulta e interação } \\
\text { com notícias, eventos, comunicados, } \\
\text { recomendações, treinamentos, protocolos, } \\
\text { solicitações, troca de informações entre } \\
\text { setores e entre profissionais), pesquisas } \\
\text { de opinião com feedback institucional, } \\
\text { colaboração para produção de conteúdo, } \\
\text { notificações push. }\end{array}$ \\
\hline
\end{tabular}

Fonte: elaborado pelos autores.

\section{RESULTADOS E DISCUSSÃO}

Dos cinquenta hospitais universitários federais do Brasil, quarenta fazem parte da Rede Ebserh, que desde 2011 faz a gestão dessas instituições. A Empresa Brasileira de Serviços Hospitalares forma a maior rede de hospitais públicos do Brasil e seu atendimento é $100 \%$ SUS que tem como finalidade prestar assistência médico-hospitalar, ambulatorial e de apoio diagnóstico e terapêutico à comunidade, de forma gratuita, bem como prestar apoio às instituições públicas federais de ensino ou instituições congêneres para que desempenhem suas missões como organizações formadoras de profissionais que oferecem ensino, pesquisa e extensão no campo da saúde pública.

A Ebserh possui uma política de comunicação institucional que preza pela integridade da identidade e imagem da rede, reforçando seus valores e objetivos estratégicos (EBSERH, 2020). Em relação à comunicação interna, a Ebserh acredita que ela deve facilitar os fluxos, promovendo integração entre todos que compõem seus quadros funcionais, incluindo gestores, empregados, servidores, estagiários, prestadores de serviço, voluntários, docentes, residentes, estudantes e menores aprendizes, em busca de comprometimento com o propósito da instituição (EBSERH, 2020).
Fomento à inovação e soluções com inteligência de dados são direcionadores que constam do mapa estratégico da rede, que traz entre seus pilares a valorização da tecnologia para otimizar processos. Diante dessas diretrizes de comunicação organizacional e a partir do que é proposto no mapa estratégico da Ebserh (EBSERH, 2020), nota-se que os princípios da Comunicação 4.0 alinham-se completamente com os direcionadores, os objetivos estratégicos e, consequentemente, com os resultados que a rede deseja entregar para a sociedade.

O Complexo Hospital de Clínicas da UFPR (CHC) é o maior hospital público do Paraná e o terceiro maior hospital universitário do país. Seu público interno possui cerca de 4.000 pessoas que atuam nas áreas médica, assistencial e administrativa bem como residentes médicos e residentes multiprofissionais. A comunicação interna é administrada pela Unidade de Comunicação do complexo, que é composta por duas profissionais de relações públicas e um publicitário. A equipe é responsável por produzir conteúdos e layouts, atualizar os veículos de comunicação e fazer toda a gestão de demandas de comunicação tanto da governança quanto dos demais setores da instituição.

Os atuais veículos de comunicação interna no CHC-UFPR são: intranet, boletins e comunicados enviados para os e-mails institucionais, 
murais, avisos em desktops e monitor de TV em uma área de circulação mista (público interno e externo). Esses veículos possuem informações relativas a protocolos administrativos, assistenciais e de ensino, eventos, treinamentos, notícias e boletins institucionais, fluxos, formulários e comunicados diversos sobre rotinas de trabalho, sendo que todos esses conteúdos são disponibilizados ao mesmo tempo para todos os integrantes, sem qualquer tipo de segmentação.

Para verificar como o público interno de um grande hospital universitário federal percebe a comunicação interna e quais suas necessidades em relação a ela, foi aplicado um questionário semiestruturado. $\bigcirc$ convite para participação na pesquisa foi publicado por duas semanas na intranet do $\mathrm{CHC}$ e no boletim diário enviado para os e-mails institucionais. Por meio de amostra qualificada, 152 questionários foram respondidos por cinco segmentos do público interno (área médica, área administrativa, área assistencial, residentes médicos e residentes multiprofissionais) que possuem três diferentes tipos de vínculo com a instituição (empregados da Ebserh, servidores da UFPR e residentes) sendo que a maioria dos participantes está vinculada à Ebserh e faz parte da área administrativa ou assistencial, conforme mostram as figuras 2 e 3 .

Devido às características das rotinas daqueles que integram as áreas médica e assistencial, bem como residentes dessas áreas, que precisam estar em constante contato com os pacientes durante sua jornada de trabalho, foi observada a dificuldade em fazer pausas para verificar os comunicados da intranet, por exemplo. Logo, essas informações internas não serão acessadas em outros momentos do dia, caso seja necessário ou desejado, exceto as informações que são enviadas por e-mail.

O gráfico representado na figura 2 mostra a baixa participação de médicos e residentes médicos neste estudo. Esse dado demonstra a dificuldade que existe em atingir e motivar esses segmentos e que um dos motivos para esse pouco engajamento é a falta de acesso aos veículos de comunicação interna, já que a pesquisa foi divulgada no site de intranet e boletim enviado por e-mail durante duas semanas consecutivas.

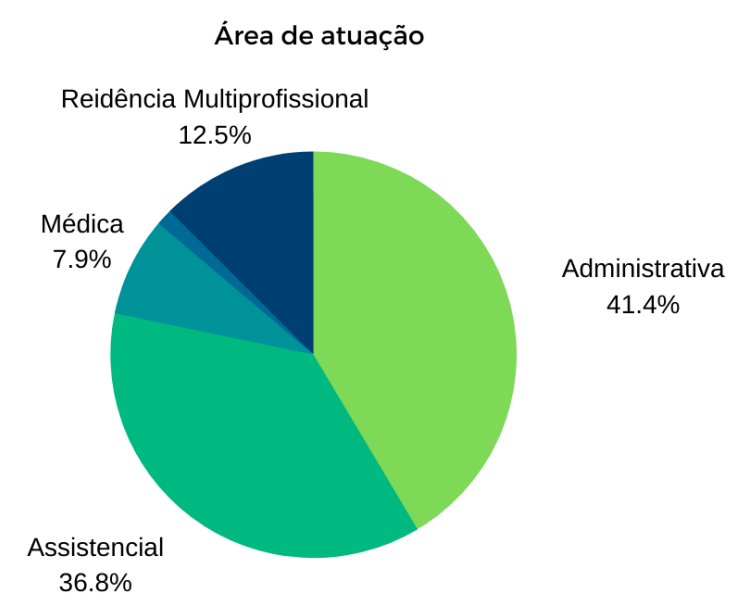

Figura 2 - Área de atuação.

Fonte: elaborado pelos autores.

Tipo de Vínculo

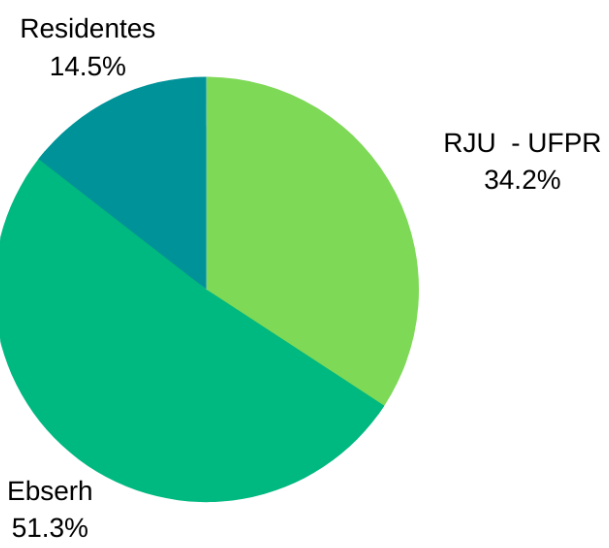

Figura 3 - Tipo de vínculo.

Fonte: elaborado pelos autores.

Além disso, os veículos atuais permitem o mínimo de interatividade via e-mails institucionais, sem proporcionar os ganhos de compartilhamento e trocas de informações e conhecimento que há por meio da inteligência coletiva e inteligência colaborativa. Não há trocas nem feedback. A comunicação torna-se verticalizada e de certa forma coercitiva. Ou seja, o público interno é apenas um receptor de mensagens, ao passo que a governança não tem como avaliar se 
as informações estão chegando a todos de forma eficaz, tampouco pode verificar se os conteúdos enviados estão de acordo com as expectativas dos profissionais e residentes.

Apesar de o Complexo Hospital de Clínicas da UFPR possuir, atualmente, cinco tipos de veículos de comunicação interna, conforme citado anteriormente, nenhum deles permite realizar comunicação dirigida, sendo que todas as informações, independentemente de serem destinadas a um único segmento, são enviadas a todos os componentes do público interno. $\bigcirc$ usuário não tem como filtrar a informação de seu interesse ou quais informações têm prioridade de leitura.

A falta de direcionamento das informações prejudica tanto a gestão do complexo hospitalar, que não consegue ter um discurso bem alinhado a cada perfil que deseja atingir, quanto o público interno, que não tem opção de verificar diretamente as informações de seu interesse, recebendo todos os dias o conteúdo institucional de forma global. Dessa forma, os profissionais da área administrativa recebem informações relativas à área médica, bem como médicos recebem protocolos administrativos inerentes apenas a chefias, por exemplo. Residentes, que apesar de já serem profissionais e também prestarem assistência a pacientes e precisarem seguir alguns protocolos administrativos, possuem um perfil diferenciado, pois estão também na condição de estudantes fazendo formação especializada. Essas características exigem mais atenção para informações focadas em ensino, pesquisa e extensão. $\bigcirc$ gráfico da figura 4, a seguir, demonstra que a maioria dos participantes deseja ter a possibilidade de filtrar os conteúdos recebidos de alguma forma.

Apesar de $50 \%$ dos participantes dizerem-se satisfeitos, em uma instituição com um público interno de cerca de 4.000 pessoas, é preocupante estimar que a comunicação interna atual não seja suficiente para tantos integrantes das grandes equipes que possui.
Você gostaria de poder filtrar os tipos de conteúdo que recebe por meio dos veículos de comunicação interna, de acordo com seu perfil e interesse?

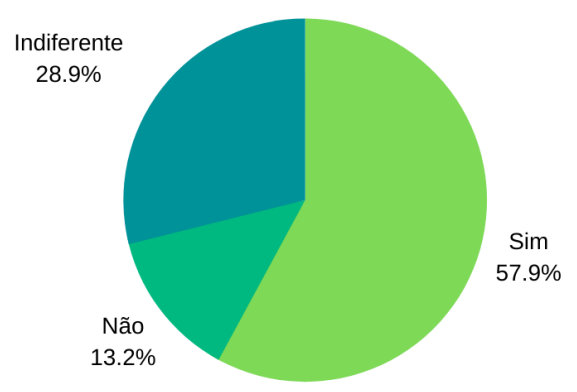

Figura 4 - Sobre o participante da pesquisa poder filtrar tipos de conteúdo.

Fonte: elaborado pelos autores.
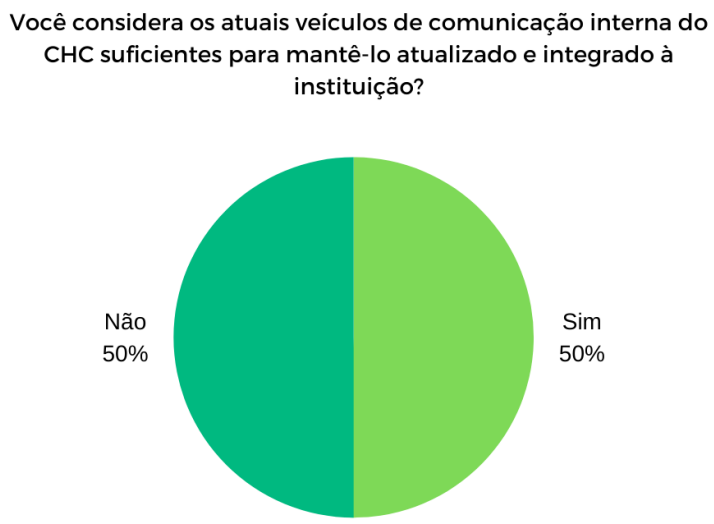

Figura 5 - Sobre o participante da pesquisa considerar os atuais veículos de comunicação do $\mathrm{CHC}$ suficientes.

Fonte: elaborado pelos autores.

Observou-se que o CHC-UFPR é uma instituição preocupada em manter seus profissionais e residentes bem informados e alinhados com as diretrizes organizacionais. No entanto, o público interno divide-se em relação à satisfação com os veículos de comunicação interna disponíveis, conforme os gráficos das figuras 6 e 7.

Ademais, os boletins diários enviados por e-mail possuem conteúdo interno diversificado, abrangendo fluxos e protocolos, comunicados da gestão e dos setores, divulgação de pesquisas, eventos e treinamentos, sendo, para $75,6 \%$ dos participantes da pesquisa, o veículo mais acessado. $\bigcirc$ fato de 
ficar disponível no e-mail institucional facilita o acesso, que pode ser feito remotamente, ao contrário dos demais veículos disponíveis. No entanto, é importante ressaltar que as informações não são alinhadas com os interesses de cada segmento, já que todos recebem os conteúdos de maneira global. Já as formas mais tradicionais de comunicação interna, como murais e intranet, representam apenas $2 \%$ e $7,9 \%$ de preferência, respectivamente, demonstrando sua pouca atratividade e consequentemente, baixa eficácia.

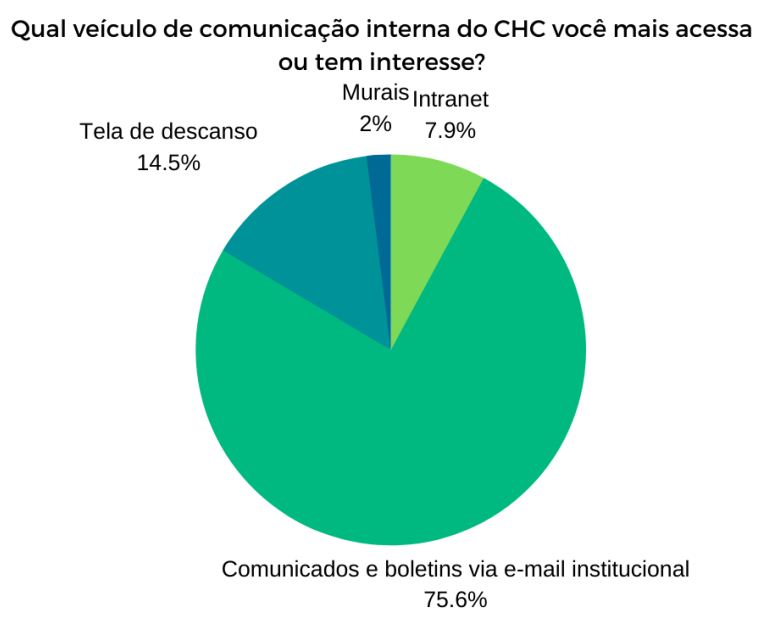

Figura 6 - Veículos de comunicação interna

Fonte: elaborado pelos autores.

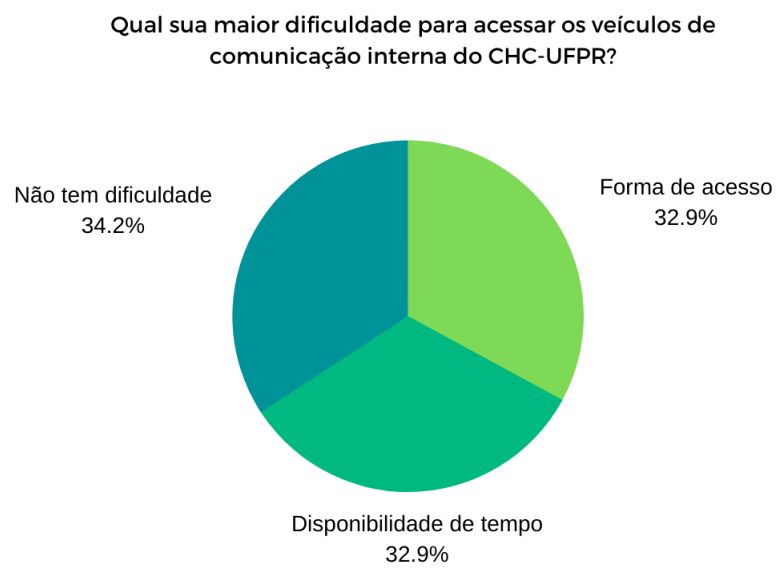

Figura 7 - Maior dificuldade para acessar os veículos de comunicação do CHC-UFPR

Fonte: elaborado pelos autores.

A maneira como os conteúdos são oferecidos é, para $32,9 \%$ dos participantes, a maior dificuldade de acesso aos veículos de comunicação interna; já a falta de disponibilidade de tempo é a causa para outros $32,9 \%$. Esses dados demonstram que apesar de $34,2 \%$ afirmarem não ter dificuldade para acessar os atuais veículos de comunicação interna, a maioria $(65,8 \%)$ percebe algum fator que pode vir a ocasionar possíveis falhas no processo comunicacional.

Concomitantemente, as formas de acesso aos veículos disponíveis são, para a maioria dos participantes, $36,2 \%$, o critério mais importante para facilitar a experiência do usuário. Tendo em vista que $65,8 \%$ dos entrevistados possui alguma dificuldade em relação à comunicação interna, e considerando os dados do gráfico a seguir, que traduz as opiniões sobre os critérios que devem ser observados para facilitar a experiência do usuário e potencializar a comunicação interna, podemos inferir que há necessidade de fazer adaptações e buscar uma alternativa que consiga facilitar o acesso dos usuários e disponibilizar conteúdos de tal forma, que mesmo aqueles com menos tempo para acessar os conteúdos divulgados, possam se manter atualizados.

Você tem interesse em interagir com seus colegas e gestores por meio de veículos de comunicação interna?

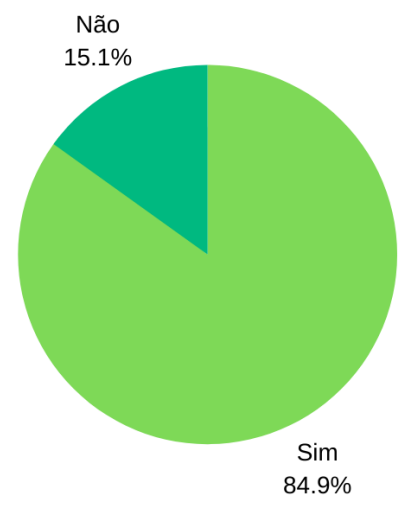

Figura 8 - Interesse em interagir com colegas e gestores.

Fonte: elaborado pelos autores. 


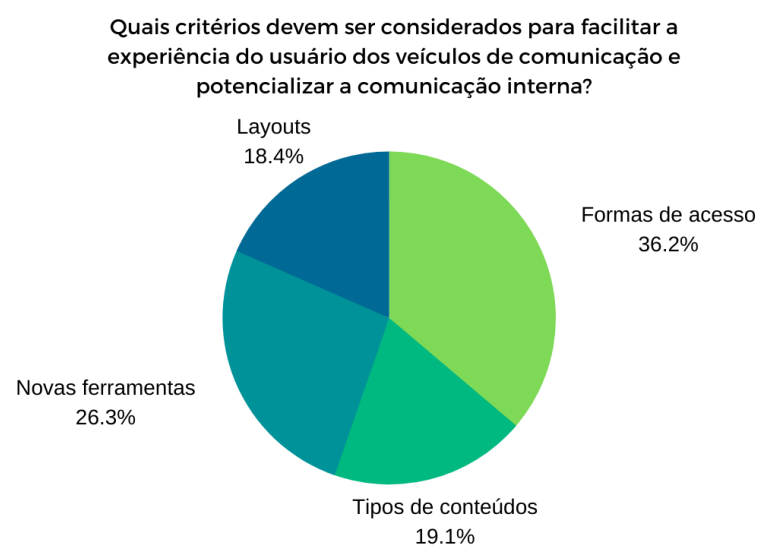

Figura 9 - Critérios para facilitar experiência do usuário dos veículos de comunicação.

Fonte: elaborado pelos autores.

Interagir com gestores e colegas de trabalho por meio dos veículos de comunicação interna é de interesse para $84,9 \%$ dos participantes. Protocolos administrativos e assistenciais seguidos por notícias institucionais e decisões da governança são os principais tipos de conteúdo que os participantes da pesquisa consideram importantes para se sentirem integrados à instituição, ao mesmo tempo que esses itens também foram citados como conteúdos fundamentais para poder desempenhar as atividades profissionais no CHC-UFPR. Essas informações já são disponibilizadas e atualizadas frequentemente pela Unidade de Comunicação da instituição.

Além desses conteúdos, os que são relacionados à valorização dos trabalhadores também foram relatados como essenciais para o bom desempenho dos profissionais, o que nos faz ratificar o quanto a motivação e o comprometimento dos profissionais são fatores relevantes e que estão estreitamente relacionados às práticas e ao desempenho das ações de comunicação interna. Foi relatado ainda que seria interessante proporcionar, por meio de um veículo de comunicação institucional, o compartilhamento de informações entre os hospitais da rede Ebserh que sejam de interesse geral de seus integrantes, além de possibilitar notificações à medida que chegam novos conteúdos. Observam-se, assim, características da comunicação 4.0 sendo sugeridas por integrantes do público interno e que são viáveis de estabelecer com o suporte de sistemas que utilizam inteligência artificial. Estamos caminhando rumo a cenários de inovação na comunicação que surgem à medida que novas necessidades ocorrem nas rotinas de profissionais diante de um novo tempo.

\section{Aprendizado de máquina e recomendação de conteúdo}

O aprendizado de máquina é a geração de aprendizado para sistemas que sejam capazes de exercer determinadas tarefas com o objetivo de promover os mais diversos tipos de soluções. A partir da incorporação de reconhecimento de padrões, gera-se um aprendizado por experiência, estruturando o conhecimento pré-existente que leva a um entendimento de aprendizado. "O reconhecimento de padrão é a descoberta de regularidades de dados através de algoritmos computacionais e uso dessas informações para classificar objetos em categorias ou classes" (THEODORIS; KOUTROUMBAS, 2006 apud STANGE, 2011, p.13). É a partir do aprendizado de máquina que se torna possível criar sistemas de recomendação de conteúdo.

Os primeiros sistemas de recomendação surgiram na década de 1990 como mecanismos para auxiliar os usuários da Internet a lidar com a grande quantidade de informações disponível (SILVA, 2014). "O primeiro tipo de conteúdo a gerar este problema para os usuários foi o e-mail. A grande quantidade de mensagens recebidas prejudicava as outras atividades do ambiente corporativo" (SILVA, 2014, p. 1). Esse é um problema que ainda ocorre em muitas instituições, inclusive no CHC-UFPR, tendo em vista que uma das principais formas de enviar informações ao público interno ainda é pelo e-mail institucional. Esse foi um dado confirmado 
na pesquisa, já que para $75,6 \%$ dos participantes, comunicados e boletins recebidos por e-mail são os conteúdos mais acessados.

Os sistemas de recomendação utilizam diversos tipos de algoritmos para tentar resolver a questão da sobrecarga de informações recebidas diariamente. Existem duas principais abordagens de recomendação de conteúdo: a abordagem baseada em conteúdo "fundamentada na área de recuperação de informação, focando principalmente na recomendação de itens com informações textuais" (ACOSTA, 2016, p. 47) e a abordagem baseada em filtragem colaborativa, cuja "essência está na troca de experiências entre as pessoas que possuem interesses comuns e os itens são filtrados baseados nas avaliações feitas pelos usuários" (ACOSTA, 2016, p. 49). $\bigcirc$ tipo de abordagem a ser utilizada depende de diversos fatores como "tipos de dados sobre os itens que estejam disponíveis, informações sobre os usuários e suas preferências, quantidade de usuários e quantidade de itens, além da esparsidade da relação usuário x item" (SILVA, 2014, p. 10).

$\mathrm{Na}$ prova de conceito realizada neste trabalho, foi utilizada a abordagem baseada em conteúdo, usando a classificação de elementos textuais a partir dos títulos e tipos de notícias publicadas nos sites do CHC-UFPR e da Ebserh, relacionando-os a cinco perfis do público interno do $\mathrm{CHC}$ de acordo com os respectivos graus de interesse de cada segmento em relação a cada tipo de conteúdo.

\section{Prova de Conceito}

Os algoritmos de classificação são utilizados em uma grande variedade de sistemas de software que processam e classificam o texto em larga escala. São exemplos de classificação os conteúdos de e-mail e conteúdos de fórum de discussão. Os algoritmos de aprendizado de máquina são capazes de classificação automática de padrões e textos. A tarefa de classificação ocorre a partir da atribuição a um documento de uma ou mais classes ou categorias com base na aplicação de um modelo que foi treinado a partir das características extraídas dos documentos utilizados no treinamento.

Com o objetivo de demonstrar como o aprendizado de máquina e seus possíveis sistemas de recomendação de conteúdo podem ser eficazes para a realização da comunicação dirigida, que é uma das grandes lacunas da comunicação interna do Complexo HC-UFPR, e que a aplicabilidade do aprendizado de máquina (inteligência artificial) está relacionada aos conceitos de comunicação 4.0, realizamos uma prova de conceito, a partir da abordagem baseada em conteúdo, com a utilização de três modelos de classificação de conteúdo de acordo com as etapas listadas a seguir.

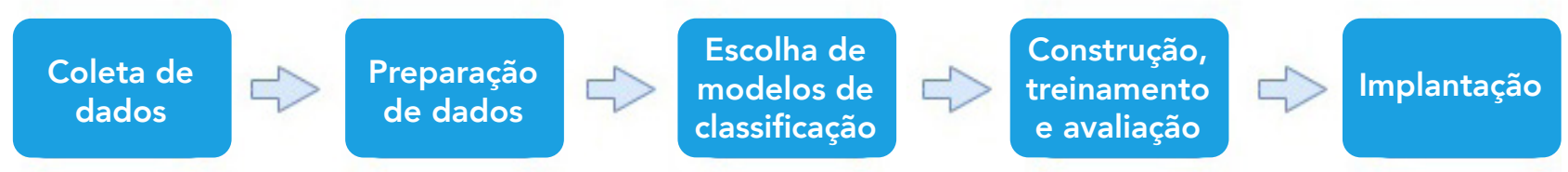

Figura 10 - Fluxo da classificação e suas respectivas etapas Fonte: elaborado pelos autores.

\section{Coleta e Preparação de dados}

Neste trabalho, a classificação foi utilizada visando automatizar o processo de seleção de conteúdo atribuindo classes às notícias, de forma que as mais relevantes foram classificadas de acordo com cada perfil, viabilizando, assim, a seleção e o encaminhamento dessas notícias conforme a sua relevância para cada segmento de público a que se destina. 
Foram reunidas 323 notícias, provenientes dos portais de Internet do CHC-UFPR e Ebserh. O objetivo foi determinar um grau de relevância das notícias para cinco áreas de atuação diferentes dentro da instituição: médica, assistencial, administrativa, residência médica e residência multiprofissional. $O$ grau de relevância varia entre 0 e 2, representando os seguintes valores:

- Valor 0, notícia com baixa ou nenhuma relevância para área.

- Valor 1, notícia com média relevância para área.

- Valor 2, notícia com alta relevância para área.

As notícias foram previamente classificadas em 11 tags: ensino, assistência, gestão, institucional, inovação, geral, eventos institucionais, humanização, eventos/ treinamentos, campanhas e Ebserh. Além da tag, o título da notícia também foi um dado importante para determinação da relevância da notícia. O gráfico a seguir apresenta os quantitativos de classificação do conjunto de notícias em função das áreas.

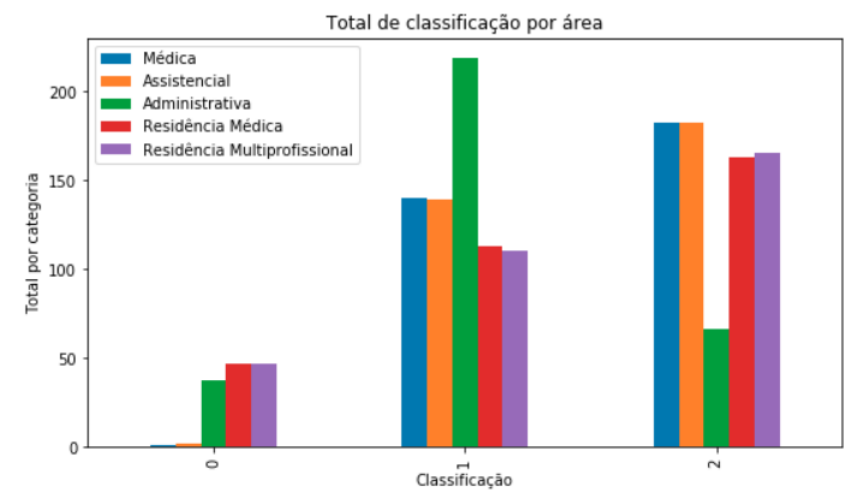

Figura 11 - Total de classificação por área Fonte: elaborado pelos autores.

A partir desses dados, observa-se que os graus de interesse das diversas áreas de atuação dos profissionais e residentes do CHC-UFPR em relação às mesmas notícias são bastante divergentes, o que demonstra ser inadequado enviar as mesmas informações para todos de forma massiva. Os dados também vão ao encontro da necessidade de possuir uma ferramenta que possa auxiliar na comunicação dirigida, assim como os sistemas de recomendação de conteúdo são capazes de realizar.

De posse desses dados, fez-se um trabaIho de tratamento do texto, com as etapas: retirada de stop words, que são palavras sem valor semântico; tokenização, visando à segmentação do texto; e a stemmização uma etapa, em que ocorre, no texto segmentado, a identificação do radical de cada palavra segmentada.

\section{Extração de características}

Em seguida, foi aplicada a codificação tf-idf (Term frequency-Inverse Document Frequency) (PALMER, 2010). Essa codificação tem o objetivo de gerar um vetor que corresponde à frequência com que os termos aparecem em cada notícia, sendo que esse vetor representa a importância do termo em função da sua frequência no documento.

$$
W_{i, J}=t f i, J \log (N d f i)
$$

Essa representação, em um espaço vetorial, viabiliza a aplicação de modelos de aprendizado de máquina para a tarefa de classificação.

\section{Escolha de modelos de classificação}

Após a geração do vetor, os algoritmos escolhidos para o estudo foram:

- Linear SVC: o Support Vector Classification (SVC) é um algoritmo de abordagem linear utilizado para reconhecimento de padrões, muito usado em problemas de classificação. Durante o treino, o algoritmo aprende o quão importante é cada data point de treinamento para representar a fronteira de decisão entre as classes. Assim, quando um novo data point é inserido, o modelo calcula a distância entre esse novo ponto e os anteriores, decidindo 
a qual classe a nova amostra pertence. Os resultados desse algoritmo vão depender fortemente da seleção dos seguintes parâmetros: função de kernel, parâmetro de regularização $\mathrm{C}$ e a norma de penalização I1 ou $\mathrm{I}$.

- MultinomialNB: o modelo é um classificador Naive Bayes, que tem classificadores bem similares aos lineares, porém, tendem a ter treinamento mais rápido. $O$ MultinomialNB assume que os dados são inteiros, em que cada feature representa um count inteiro da quantidade de algo, como palavras em um texto. Tal modelo leva em consideração a média de valor de cada feature para cada classe em seu treinamento. $O$ parâmetro de mais importância nesse algoritmo é alpha, que controla a complexidade do modelo, nesse caso, um alpha grande representa um modelo menos complexo.

- RandomForest: o modelo consiste basicamente em uma coleção de decision trees, em que cada árvore é um pouco diferente das outras. Tal abordagem visa ter uma generalização maior e diminuir um dos grandes problemas das decision trees, que é o overfitting. Seus parâmetros importantes são: n_estimators, que é o número de árvores; max_features, responsável por determinar o grau de aleatoriedade de cada árvore; e max_depth, que determina o máximo galhos da árvore.
Esses modelos foram escolhidos por demonstrarem bons resultados na literatura com trabalhos envolvendo análise de texto.

\section{Treinamento}

A abordagem de treinamento baseou-se em utilizar os três modelos descritos acima, focando uma área por vez, ou seja, foi usado um classificador específico para cada área, todos com os mesmos inputs, mas classes (targets) diferentes. O percentual de treinamento e teste variou nas seguintes proporções: 80/20, 70/30, 60/40, sendo o primeiro valor o percentual de treinamento e o seguinte de teste.

\section{Ambiente de desenvolvimento}

O estudo foi desenvolvido em uma máquina com sistema operacional windows 10, utilizando Jupyter notebook v4.4.0, a linguagem Python v3.7.3 e as bibliotecas: pandas v0.24.2, numpy v1.16.2, nltk v3.4 e sklearn scikit-learn v0.23.2.

\section{Resultados da prova de conceito}

A seguir, seguem os resultados obtidos a partir de cada modelo e proporção de treinamento:

Tabela 1 - Resultados da prova de conceito

\begin{tabular}{|l|c|c|c|c|c|c|c|c|c|}
\hline & \multicolumn{3}{|c|}{ Linear SVC } & \multicolumn{3}{c|}{ MultinomialNB } & \multicolumn{3}{c|}{ RandomForest } \\
\hline Área/Modelo & $\mathbf{8 0 / 2 0}$ & $\mathbf{7 0 / 3 0}$ & $\mathbf{6 0 / 4 0}$ & $\mathbf{8 0 / 2 0}$ & $\mathbf{7 0 / 3 0}$ & $\mathbf{6 0 / 4 0}$ & $\mathbf{8 0 / 2 0}$ & $\mathbf{7 0 / 3 0}$ & $\mathbf{6 0 / 4 0}$ \\
\hline médica & $73,84 \%$ & $75,25 \%$ & $72,30 \%$ & $75,38 \%$ & $72,16 \%$ & $72,30 \%$ & $72,30 \%$ & $70,10 \%$ & $72,30 \%$ \\
\hline assistencial & $78,64 \%$ & $74,22 \%$ & $73,84 \%$ & $72,30 \%$ & $71,13 \%$ & $73,84 \%$ & $75,38 \%$ & $72,16 \%$ & $69,23 \%$ \\
\hline administrativa & $69,23 \%$ & $61,85 \%$ & $66,15 \%$ & $50,76 \%$ & $57,73 \%$ & $60,00 \%$ & $73,84 \%$ & $70,10 \%$ & $66,15 \%$ \\
\hline residência & $69,23 \%$ & $64,94 \%$ & $63,07 \%$ & $72,30 \%$ & $68,04 \%$ & $62,30 \%$ & $67,69 \%$ & $63,91 \%$ & $61,53 \%$ \\
\hline multiprofissional & $72,30 \%$ & $69,07 \%$ & $63,84 \%$ & $69,23 \%$ & $70,10 \%$ & $64,61 \%$ & $64,61 \%$ & $64,94 \%$ & $63,84 \%$ \\
\hline Media & $72,65 \%$ & $69,07 \%$ & $67,84 \%$ & $67,99 \%$ & $67,83 \%$ & $66,61 \%$ & $70,76 \%$ & $68,24 \%$ & $66,61 \%$ \\
\hline
\end{tabular}

Fonte: elaborado pelos autores. 
Nas figuras a seguir as matrizes de confusão que apresentam os melhores resultados de cada área. É importante destacar que tanto para área médica como a área assistencial, havia apenas uma notícia classificada com relevância 0 , então, tal classe não aparece nas matrizes de confusão das respectivas áreas.

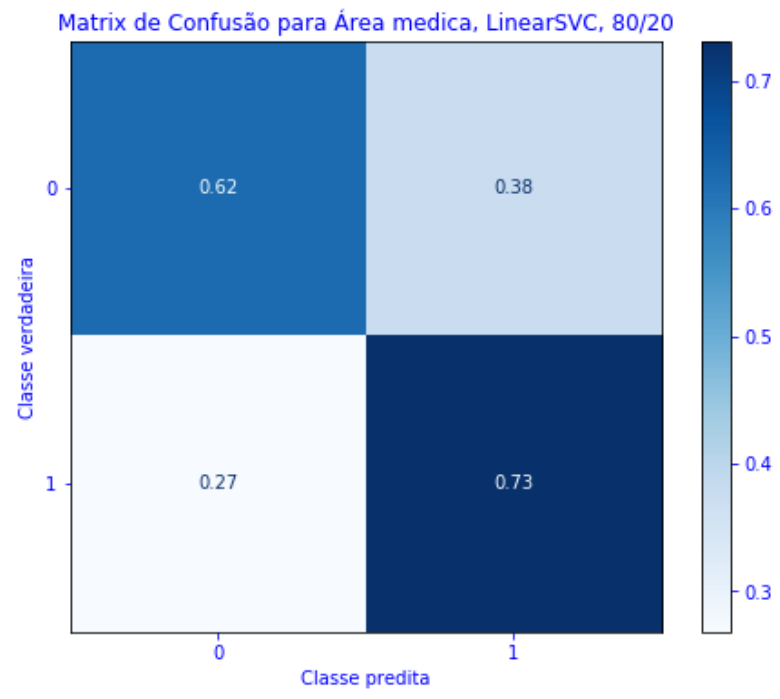

Figura 12 - Matriz confusão para área médica, com algoritmo Linear SVC e split de treinamento-teste 80/20 Fonte: elaborado pelos autores.

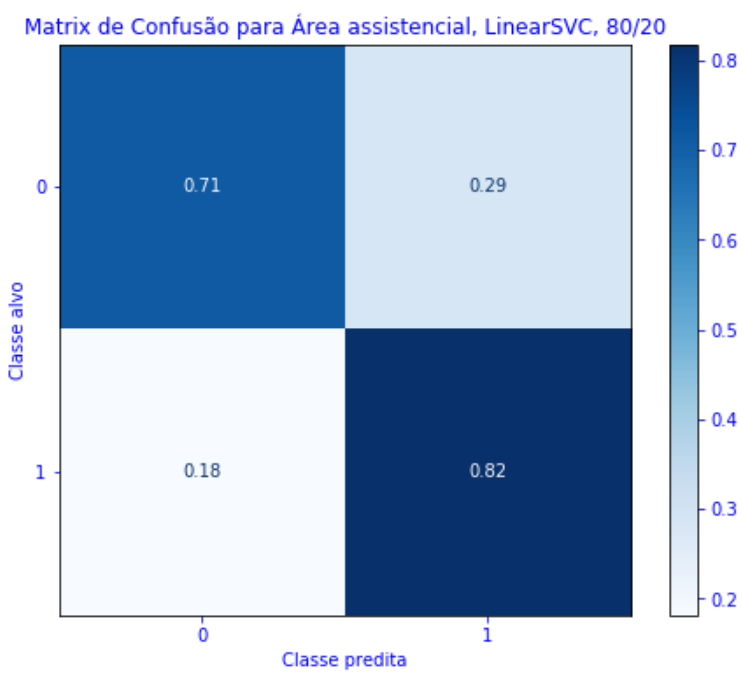

Figura 13 - Matriz confusão para área assistencial, com algoritmo Linear SVC e split de treinamento-teste 80/20 Fonte: elaborado pelos autores.

Pôde-se observar que, para a área médica, o algoritmo teve uma taxa de acerto de $62 \%$ para classe 1; e 73\% para classe 2. Para a área assistencial, o algoritmo teve uma taxa de acerto de $71 \%$ para a classe 1 e $82 \%$ para a classe 2 .

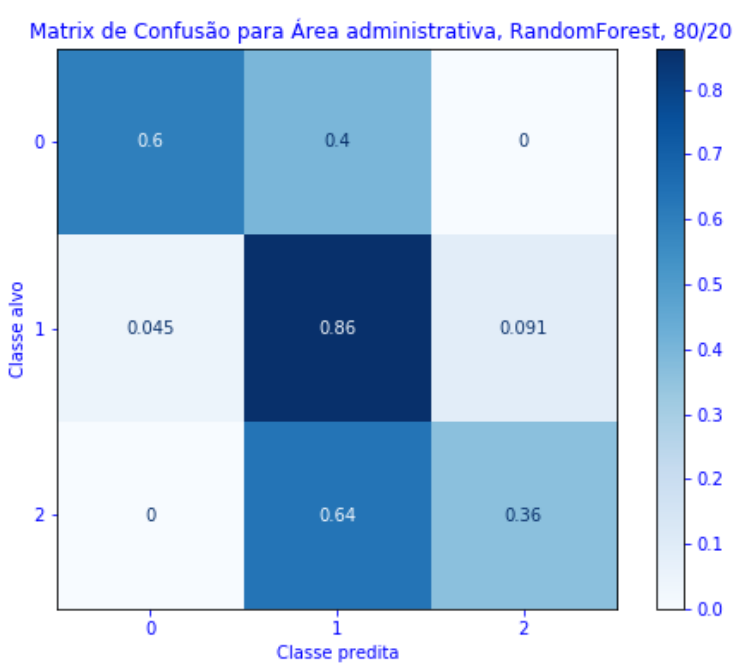

Figura 14 - Matriz confusão para área administrativa, com algoritmo RandomForest e split de treinamento-teste 80/20 Fonte: elaborado pelos autores.

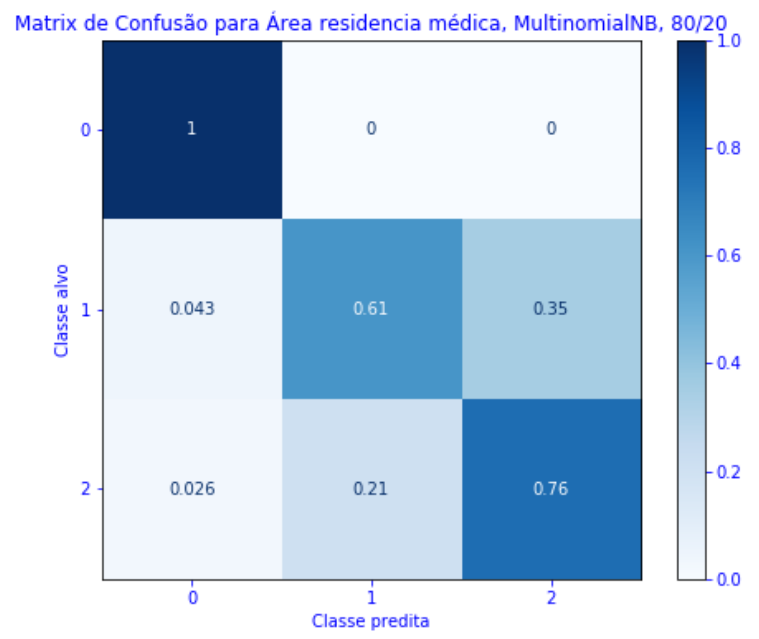

Figura 15 - Matriz confusão para área residência médica, com algoritmo MultinomialNB e split de treinamento-teste 80/20 Fonte: elaborado pelos autores.

Observa-se, nas figuras 14 e 15, que há três colunas, pois, ao contrário das duas classes anteriores, temos mais notícias com relevância classificada como $0 . \mathrm{Na}$ área administrativa, tivemos uma acurácia de $60 \%$ para classe $0 ; 86 \%$ para classe 1 ; e apenas $36 \%$ para classe 2 . 
Para a área residência médica, tivemos as taxas de acerto de $100 \%$ para classe 0; 61\% para classe 1; e 76\% para classe 2.

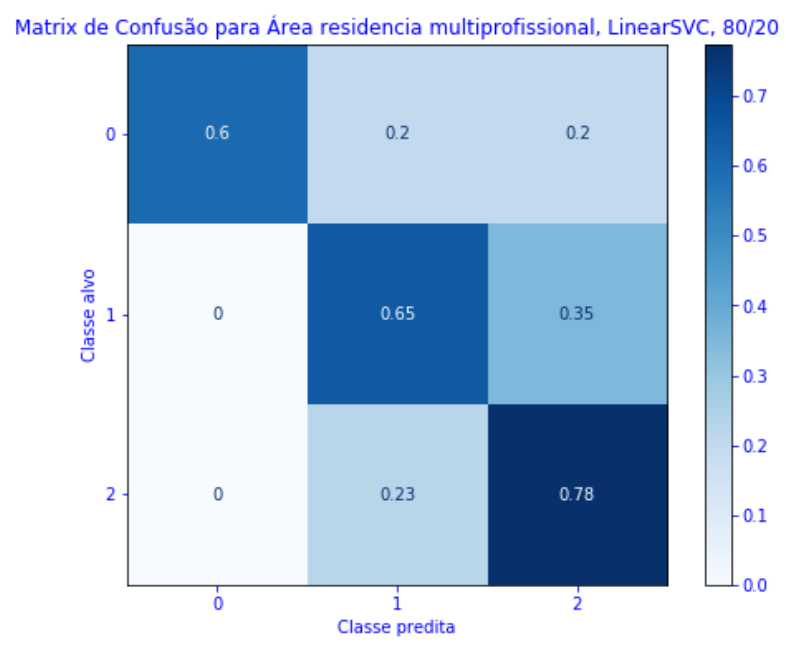

Figura 16 - Matriz confusão para área residência multiprofissional, com algoritmo Linear SVC e split de treinamento-teste 80/20

Fonte: elaborado pelos autores.

Para área residência multiprofissional, observam-se taxas de acerto de $60 \%$ para a classe 0; 65\% para a classe 1; e 78\% para a classe 2 . A partir dos resultados obtidos na prova de conceito, pode-se afirmar que trabalhar com recomendação de conteúdo classificado de forma autônoma, pelo uso de aprendizado de máquina, para realizar uma comunicação interna dirigida, é uma solução viável e que traz eficácia à medida que recomenda informações de acordo com os interesses e as necessidades de cada segmento do público interno de uma instituição, proporcionando mais agilidade e assertividade na comunicação e, consequentemente, mais satisfação dos usuários.

Os sistemas de recomendação de conteúdo e o aprendizado de máquina podem ser aprimorados à medida que forem sendo utilizados e avaliados, proporcionando cada vez mais assertividade e satisfação aos usuários e à gestão. Tendo em vista que esses sistemas possibilitam também a verificação de métricas, que, por sua vez, geram dados e informações, acabam por se tornar não só um instrumento para a inserção na comunicação 4.0 como também uma ferramenta estratégica de gestão.

\section{CONCLUSÕES}

Os avanços tecnológicos que ocorreram nestas últimas décadas, especialmente nos sistemas de informação e comunicação, possibilitaram um cenário de grandes transformações. Essas mudanças desencadearam a formação de uma nova sociedade em que a instantaneidade e rapidez da comunicação trouxeram alterações aos padrões culturais das pessoas e organizações. No caso dos hospitais universitários - que são instituições extremamente complexas e heterogêneas e possuem procedimentos, serviços, processos administrativos, perfis profissionais e rotinas que circundam as mais diversas áreas do conhecimento -, exercer a comunicação interna de forma eficaz, ágil e abrangente é um grande desafio.

O amplo volume de informações que circula diariamente e precisa ser de conhecimento dos profissionais e residentes dos hospitais universitários nem sempre é acessível nos momentos e prazos previstos, pois a natureza das atividades desses profissionais, muitas vezes, impede que consultem dados disponíveis apenas em sistemas internos e sites de intranet. Diante desse cenário, novas técnicas precisam fazer parte dos protocolos de comunicação interna dessas organizações.

Por meio dos dados obtidos com pesquisa aplicada no Complexo HC-UFPR, observamos que $65,8 \%$ dos participantes possuem alguma dificuldade para acessar os veículos de comunicação interna da instituição; e $26,3 \%$ expressam que novas ferramentas de comunicação devem ser ofertadas para facilitar a experiência do usuário e potencializar a comunicação interna. Ao mesmo tempo que $57,9 \%$ gostariam de poder filtrar os tipos de conteúdo que recebem, 84,9\% desejam interagir com colegas e gestores por meio dos veículos de comunicação interna, sendo que atualmente não é possível.

A partir desse cenário e da avaliação dos atuais veículos de comunicação disponíveis no CHC-UFPR, observa-se que é necessário 
o planejamento e a implementação de uma solução inovadora de comunicação interna que venha ao encontro das necessidades e dos perfis de todos os segmentos do público interno, acompanhando as mudanças culturais e tendências propostas pela comunicação 4.0. Mais do que estratégica, a comunicação precisa ser transparente e simétrica.

A falta da comunicação dirigida dificulta muito a rotina dos profissionais e residentes de um grande complexo hospitalar, já que recebem uma grande quantidade de dados diariamente e precisam fazer individualmente a seleção dos assuntos que Ihes são destinados. Mesmo assim, 75,7\% dos participantes da pesquisa afirmam que os comunicados e materiais recebidos via e-mail institucional são a principal forma de acesso às informações institucionais, sendo que os demais meios são murais, intranet, telas de descanso dos computadores e TV em área de circulação coletiva. Por isso, os elementos da comunicação 4.0, como a gestão de dados por meio de sistemas que utilizem inteligência artificial, o aprendizado de máquina e sistemas de recomendação de conteúdo, são uma alternativa promissora.

A prova de conceito para aprendizado de máquina desenvolvida neste trabalho mostrou que existe eficácia nessa tecnologia para executar a comunicação dirigida à medida que consegue oferecer aos usuários as informações de acordo com seus perfis e graus de interesse. Assim, é possível adotar os elementos da comunicação 4.0 como uma prática internalizada e legítima, conectando e transformando pessoas e processos organizacionais.

Durante a aplicação da metodologia desta pesquisa, foram observadas algumas limitações, como o pouco volume de notícias disponível no site de Internet do CHC-UFPR, o que impediu que tivéssemos resultados melhores na prova de conceito. A pouca participação de médicos e residentes médicos para responder os questionários também foi outra fragilidade, ao mesmo tempo que demonstrou como há um baixo engajamento desses segmentos em ações propostas pelos veículos de comunicação interna. Porém, a identificação da necessidade de realizar comunicação dirigida e a proposta de utilização da comunicação 4.0 a partir do aprendizado de máquina e consequente recomendação de conteúdo, de acordo com a viabilidade validada na prova de conceito, é um primeiro passo para o início de uma grande transformação na comunicação interna do Complexo HC da UFPR, que pode ter aplicabilidade nos demais hospitais universitários da rede Ebserh. Levando em consideração as características da atual comunicação interna do Complexo Hospital de Clínicas da UFPR, as diretrizes de comunicação interna, bem como descritores estratégicos da rede Ebserh, e as necessidades eminentes de readequação das estratégias e ações de comunicação interna dos hospitais universitários federais, de acordo com os princípios da comunicação 4.0, é possível deduzir que uma solução factível, inovadora e eficiente seja a implementação de um veículo de comunicação que utilize o aprendizado de máquina para fazer recomendação de conteúdo. Quando a informação chega mais rápido e com mais qualidade de conteúdo, alcança um número maior de pessoas e é direcionada aos segmentos de público de acordo com os interesses da instituição e dos receptores, obtêm-se melhorias no alinhamento estratégico e até mesmo na produtividade das equipes. A prova de conceito trabalhou apenas com a abordagem baseada em conteúdo, mas implementar um sistema que utilize também a abordagem colaborativa é importante para gerar mais interação e ter recomendações ainda mais assertivas.

Como proposta para trabalhos futuros, acredita-se que a comunicação interna pode ser planejada a partir de uma única plataforma que reúna todos os conteúdos de interesse dos profissionais e residentes. Essa plataforma poderá utilizar não só sistemas de recomendação de conteúdo como também diversos outros elementos da comunicação 4.0, proporcionando interatividade entre os 
usuários e feedback entre os diversos níveis hierárquicos da instituição. Com a democratização do acesso à internet, o processo de comunicação entre públicos e instituições tem a possibilidade de tornar-se rápido e fácil, sem depender da estrutura física da instituição. Desse modo, é estratégico facilitar os processos de comunicação interna, oferecendo aos profissionais da saúde e residentes uma solução que facilite o acesso à informação, já que ela acompanhará o usuário aonde quer que ele vá. Assim, uma rede social corporativa, que possa ser acessada remotamente por meio de dispositivos móveis, pode ser uma solução para as dificuldades que existem em relação ao acesso às informações e à interatividade entre os diversos níveis hierárquicos.

A partir do momento que os profissionais de saúde e residentes de um grande hospital universitário passam a ter mais participações e recursos de comunicação interna, a qualidade no atendimento pode ser elevada. Ter acesso a ferramentas de comunicação eficazes e democráticas gera comprometimento institucional, refletindo na assistência aos pacientes e nos resultados de gestão ao elevar os índices de produtividade e qualidade de serviços, bem como redução de desperdícios e custos. $\bigcirc$ estudo traz inovação para a comunicação na saúde pública, pois propõe uma solução inédita com a utilização de sistema de recomendação de conteúdo para os hospitais universitários federais do país. Contribui com a ciência ao avaliar e identificar carências e expectativas dos profissionais de saúde em relação à comunicação interna realizada em um hospital universitário, que se mostra como condição fundamental para o desenvolvimento e o cumprimento de protocolos de gestão e assistência, refletidos diretamente nos milhares de pacientes assistidos pelo sistema de saúde pública. Os participantes tiveram a oportunidade de colaborar com as melhorias na comunicação institucional de um dos maiores hospitais públicos do Brasil, gerando, por meio de uma análise individual, dados que são fundamentais para o desenvolvimento de uma solução pioneira para hospitais universitários federais.

Este trabalho demonstra que - por meio da gestão de dados e utilização de recursos de inteligência artificial, como a recomendação de conteúdo e aprendizado de máquina - é possível oferecer uma comunicação interna menos coercitiva, que seja mais interativa, assertiva e colaborativa. Pode-se, ainda, auxiliar nas tomadas de decisão nas rotinas profissionais e na gestão, gerar engajamento e efetividade, o que refletirá na qualidade da assistência e ensino prestados à sociedade. 


\section{REFERÊNCIAS}

ACOSTA, O.C.; REATEGUE, E.B.; BEHAR, P.A. Recomendação de conteúdo em um ambiente colaborativo de aprendizagem baseada em projetos. 2016. Tese (Doutorado) - Universidade Federal do Rio Grande do Sul, Porto Alegre, 2016.

ASTIGARRAGA, E. et al. Umap, inteligencia colectiva extraída de las redes sociales. El professional de la información, v. 20, n. 5.2011.

BAUSE, M. et al. Design for health 4.0: exploration of a new area. International Conference on Engineering Design, ICED19 5-8 AUGUST 2019, DELFT, THE NETHERLANDS, 2019.

CAJAZEIRA, J.E.R.; CARDOSO, C. COMUNICAÇÃO e Inovação: Correlações e Dependências. In: CONGRESSO BRASILEIRO CIENTÍFICO DE COMUNICAÇÃO ORGANIZACIONAL E DE RELAÇÕES PÚBLICAS. 2009. Anais [...], São Paulo, 2009.

COELHO, P.M.N. Rumo à Indústria 4.0. 2016. Dissertação (Mestrado) - Universidade de Coimbra, 2016.

COSTA, D. Não existe gestão sem comunicação. Porto Alegre; São Paulo: Dublinense, 2015.

CURVELLO, J.J.A. Comunicação Interna e Cultura organizacional. Brasília: Casa das Musas, 2012.

DA COSTA BUENO, W. Comunicação interna e liderança aberta: os desafios de incorporar a geração Y e as mídias sociais. Revista Brasileira de Comunicação Organizacional e Relações Públicas, v. 10, n. 19, 2013.

DAVENPORT, T. Big Data no Trabalho: derrubando mitos e descobrindo oportunidades. Rio de Janeiro. Alta Books. 2017.

DAVID, G. Internal Communication - Essential Component Of Crisis Communication. Journal of Media Research, 2011.

EMPRESA BRASILEIRA DE SERVIÇOS HOSPITALARES. Disponível em: https://www.gov.br/ebserh/ pt-br/governanca/gestao-estrategica/mapa-estrategico/mapa-estrategico-ebserh.png. Acesso em: 25 nov. 2020.

EMPRESA BRASILEIRA DE SERVIÇOS HOSPITALARES. Disponível em: https://www.gov.br/ebserh/ $\mathrm{pt-br/comunicacao/legislacao-e-normas-de-comunicacao/politica-de-comunicacao-institucional.}$ Acesso em: 25 nov. 2020

GÉRON, A. Mãos à Obra: Aprendizado de Máquina com Scikit-Learn e TensorFlow: Conceitos, Ferramentas e Técnicas Para a Construção de Sistemas Inteligentes. Rio de Janeiro: Alta Books, 2019.

GOMES, E.; BRAGA, F. Inteligência competitiva em tempos de big data: analisando informações e identificando tendências em tempo real. Rio de Janeiro: Alta Books, 2017. 
LÉVY, P. A inteligência coletiva: por uma antropologia do ciberespaço. 4. ed. São Paulo: Loyola, 2003.

LUERSEN, E.H. A apropriação da teoria hipodérmica pela figura do controlador social da obra ficcional distópica. Revista Temática, v. 9, n. 7, 2013.

MARCHIORI, M. Os desafios da comunicação interna nas organizações. Conexão - Comunicação e Cultura, UCS, Caxias do Sul, v.9, n. 17, jan./jun.2010.

MINISTÉRIO DA EDUCAÇÃO. Disponível em: http://www.portal.mec.gov.br/hospitaisuniversitarios. Acesso em: 25 nov. 2020.

MIURA, J. Os Desafios para Construção de uma Ciência 2.0. 2012. Dissertação (Mestrado em Multimédia) - Universidade do Porto, Porto, 2012.

MULLER, A. C.; GUIDO, S. Introduction to Machine Learning with Python. 1. ed. [S.I.]: O'Reilly, 2017.

NELLI, F. Machine Learning with scikit-learn. Python Data Analytics. Apress, Berkeley, CA, 2018.

OLIVEIRA, I.; ALENCAR, T. A dinâmica comunicativa no ambiente interno das organizações: interrelação da comunicação formal com a comunicação informal. Revista Brasileira de Comunicação Organizacional e Relações Públicas, v. 10, n. 19, 2013.

PALMER, D. D. Text preprocessing. In Handbook of natural language processing. 2. ed. Chapman and Hall/CRC, 2010.

PENHAKI, J. Soft Skills na Indústria 4.0. 2019. Dissertação (Mestrado) - Universidade Tecnológica do Paraná, Curitiba, 2019.

PIERANGELO, A.; MERONE, M.; SODA, P. Hospital 4.0 and its innovation in methodologies and technologies. Published in: IEEE 31st International Symposium on Computer-Based Medical Systems (CBMS), 2018.

SARKA, $\mathrm{H}$. Tolls of internal communication from knowledge transfer perspective. Journal of Competitiveness, v. 6, n. 4, 2014.

SILVA, R.G.N. Sistema de Recomendação baseado em conteúdo textual: avaliação e comparação. 2014. Dissertação (Mestrado) - Universidade Federal da Bahia/ Universidade Estadual de Feira de Santana, Salvador, 2014.

STANGE, R.L. Adaptatividade em aprendizagem de máquina: conceitos e estudo de caso. 2011. Dissertação (Mestrado) - Escola Politécnica da Universidade de São Paulo, São Paulo,2011.

THIMBLEDY, H. Technology and the Future of Healthcare. Journal of Public Health Research, 2013.

WHITE, C.; VANCE, A.; STAFFORD, G. InternalCommunication,Information, Satisfaction and Community Sense: The Effect of Personal Influence. Journal of Public Relations Research, v. 22, 2020. 